Goldschmidt 2021 Abstract

https://doi.org/10.7185/gold2021.4834

\section{Hydrothermal REE partitioning between fluorite and aqueous fluids: insights from experiments and natural fluid inclusions}

\author{
MADISON ROSE PAYNE ${ }^{1}$, ALEXANDER GYSI ${ }^{2}$ AND \\ NICOLE C HURTIG ${ }^{2}$ \\ ${ }^{1}$ New Mexico Institute of Mining \& Technology \\ ${ }^{2}$ New Mexico Institute of Mining and Technology \\ Presenting Author: madison.payne@student.nmt.edu
}

Rare earth element (REE) deposits are found in association with carbonatite and alkaline systems, where metasomatism plays a significant role in the late-stage transport and enrichment of REE [1]. Fluorite is a common gangue mineral in these mineral deposits and can incorporate varying REE concentrations by substitutions of $\mathrm{REE}^{3+}$ for $\mathrm{Ca}^{2+}$. Fluorite-hosted fluid inclusions contain significant REE concentrations [2], providing a potential record of the hydrothermal ore-forming fluids. The fluorite-fluid REE partitioning mechanisms, however, are largely unknown. To date, only one study [3] measured the partitioning of REE between fluorite and aqueous fluid at $60{ }^{\circ} \mathrm{C}$. Here, we evaluate these REE partitioning mechanisms by combining laboratory experiments with characteristics of natural fluid inclusions that provide a range of salinities and homogenization temperatures relevant to natural systems.

Batch-type experiments will be conducted between 100 and $250{ }^{\circ} \mathrm{C}$ in Teflon-lined reactors, in which millimeter-sized natural fluorite crystals (Cooke's Peak, New Mexico) will be reacted with fluids of varying initial REE concentration, $\mathrm{pH}$, and salinity. Kinetic experiments were carried out at $150{ }^{\circ} \mathrm{C}$ to test for attainment of a steady state between the fluorite crystals and the aqueous solutions. The reacted fluorite crystals will be studied using SEM, CL and EMPA. Major cations and anions in the quenched fluids will be analyzed using IC and ICP-OES; REE will be determined using solution ICP-MS. These results will permit deriving REE fluorite-fluid partition coefficients.

Fluid inclusions in hydrothermal fluorite veins from the fluorite-bastnäsite REE deposits in the Gallinas Mountains in New Mexico are studied to constrain temperatures, salinities, and REE concentrations of hydrothermal ore-forming fluids in alkaline systems. Fluid inclusion assemblages were identified in growth zones and will be further studied using microthermometry. Previous studies found maximum temperatures of $400{ }^{\circ} \mathrm{C}$ in sulfate-rich $\mathrm{NaCl}-\mathrm{KCl}$ brines [4]. The goal will be to link partition coefficients derived from the experiments to the REE partitioning behavior found in the natural fluorite.

[1] Gysi et al. (2016), Econ. Geol. 111, 1241-1276; [2] Vasyukova and Williams-Jones (2018) Chem. Geol. 483, 385396; [3] van Hinsberg et al. (2010), Geology 38, 847-850; [4] Williams-Jones et al. (2000), Econ. Geol. 95, 327-341.

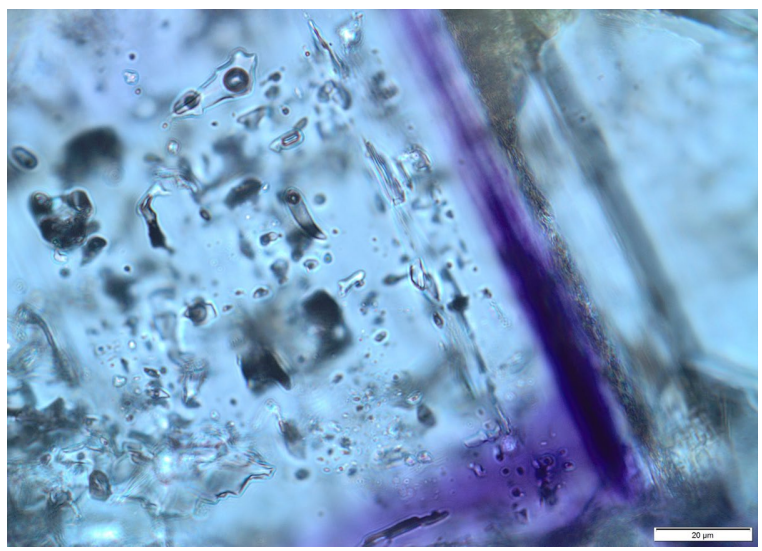

